\title{
AVALIAÇÃO DE CONHECIMENTO PRÉVIO SOBRE A DOENÇA FALCIFORME ENTRE PARTICIPANTES DE SEMINÁRIO DE ODONTOLOGIA
}

\author{
Ilanna Jamile de Souza Castro*, Emanuel Braga Rêgo**, Diane Vasconcelos de Santana Oliveira*, \\ André Wilson Machado***, Cristiano Augusto Trein ${ }^{* * * *}$, Ana Stela Goldbeck ${ }^{* * * *}$ \\ Autor correspondente: Ilanna Jamile de Souza Castro - ilanna.castro@hotmail.com \\ * Acadêmica do curso de Odontologia na Universidade Federal da Bahia \\ ** Doutor em Ortodontia pela Universidade de Hiroshima, professor de Ortodontia e Odontopediatria da Universidade \\ Federal da Bahia, vice-presidente da Associação Brasiliense de Ex-Bolsistas Brasil-Japão \\ *** Doutor em Ortodontia pela Universidade Estadual Paulista Júlio de Mesquita Filho/Universidade da Califórnia \\ Los Angeles e professor de Ortodontia da Universidade Federal da Bahia \\ **** Doutor em Engenharia pela Universidade de Kyoto e presidente da Associação Brasiliense de Ex-Bolsistas Brasil-Japão \\ ***** Farmacêutica e bioquímica, mestre em Antropologia Social pela Universidade Federal do Rio Grande do Sul, \\ especialista em Triagem Neonatal pela Japan International Cooperation Agency e membro da Associação Brasiliense de \\ Ex-Bolsistas Brasil-Japão
}

\section{Resumo}

A Doença Falciforme (DF) é responsável por um elevado índice de mortalidade e morbidade no Brasil. É sabido que há diversas manifestações bucais e repercussões desta condição no tratamento odontológico. No entanto, pouco se conhece sobre o grau de conhecimento dos dentistas sobre esta enfermidade. O objetivo deste artigo foi avaliar o grau de conhecimento e o perfil de diferentes ouvintes, a partir de um questionário distribuído durante o seminário "O papel da Odontologia no contexto da atenção integral à DF", realizado em um curso de Odontologia de uma instituição de ensino superior pública. Os resultados da presente pesquisa revelaram que, de uma forma geral, a maioria dos respondentes consideram ter pouco conhecimento sobre DF, apesar de possuírem uma grande disposição em aprender. Constatou-se também que há maior interesse neste tema por parte dos profissionais já formados, provavelmente em decorrência da demanda por atendimento de pacientes com DF no dia-a-dia da clínica, visto que a Bahia é o Estado brasileiro que apresenta a maior prevalência. Deste modo, evidencia-se que ainda há carência de informações e muitas dúvidas sobre o papel da Odontologia no contexto da atenção integral à DF. Uma maior atenção na formação do dentista no tocante às doenças de grande prevalência no Brasil pode promover a elaboração de uma agenda positiva, contemplando melhores condutas e protocolos terapêuticos adequados, traduzindo-se em um benefício real para o paciente.

Palavras-chave: Doença Falciforme; Odontologia; Atenção à Saúde. 


\title{
SICKLE CELL DISEASE PRIOR KNOWLEGDE ASSESSMENT AMONG DENTISTRY SEMINAR PARTICIPANTS
}

\begin{abstract}
Sickle Cell Disease (SCD) is responsible for high mortality and morbidity in Brazil. It is known that SCD promotes several oral manifestations and impacts directly on the dental treatment approach. However, there is little information concerning the dentists' prior knowledge about the illness. The aim of the present study is to assess the level of knowledge and the profile of different respondents, by means of a questionnaire applied during the seminar "O papel da Odontologia no contexto da atenção integral à DF" hosted in a dental course of a public higher education institution. The results of the present study have shown that, in general, the majority of the respondents stated that they have insufficient information about SCD, in spite of the great interest in learning. It was also found a greater interest among the graduated dentists, probably due to the fact that they have already experienced the treatment on SCD patient, since Bahia State presents the greater prevalence of the disease in Brazil. In this context, it seems clear that there is a lack of information and many doubts about the role of dentistry in the health care of patients with SCD. High prevalence diseases in Brazil should be addressed with depth more often in dentistry higher education programs. Better treatment approaches and protocols for dental care of patients with SCD are antecipated.
\end{abstract}

Keywords: Sickle Cell Disease; Dentistry; Health Care.

\section{INTRODUÇÃO}

A Doença Falciforme (DF) é a enfermidade hereditária mais prevalente no Brasil. ${ }^{(1)}$ Foi originada na África e apresenta, portanto, maior prevalência nas populações afro-descendentes. No Brasil, estima-se que acometa cerca de $0,1 \%$ a $0,3 \%$ da população. (2) No Estado da Bahia, há um foco endêmico da doença, onde foi estimada uma frequência de portadores do traço falcêmico de $5,5 \%$ na população geral, chegando a $6,3 \%$ na população de afro-descendentes. ${ }^{(2)}$

A DF consiste em uma alteração de um gene estrutural originando uma hemoglobina anômala Hemoglobina S (ouHbS). (3) Esta mutação provoca um alongamento da hemácia, adquirindo um formato de "foice". (4) As hemácias alteradas tem dificuldade de circular pelos vasos sanguíneos, redu- zindo a quantidade de oxigênio transportado. Em adição, esta alteração reduz a vida útil da célula que passa de 120 a aproximadamente 20 dias, aumentando sua deposição nas paredes endoteliais causando vasoclusão e consequente anóxia tecidual, infarto, necrose e dor nas áreas afetadas. . $^{(4,5)}$

Trata-se de uma doença com elevada mortalidade e morbidade. A sintomatologia da DF compreende isquemia, dor, necrose, danos permanentes aos tecidos e órgãos e disfunções. ${ }^{(6)}$ A complicação mais relatada pelos portadores e a principal causa de internação é a crise álgica, consequência da vasoclusão e dificuldade de oxigenação tecidual. ${ }^{(2,4)}$

A DF tem implicações relevantes para a Odontologia, pois pode causar alterações bucais como hipomaturação e hipomineralização de esmalte e 
dentina, presença de calcificações e necrose pulpar devido à trombose dos vasos, hipercementose, palidez de mucosa, língua lisa, descorada e despapilada, retardo na erupção em ambas as dentições, parestesia do nervo alveolar inferior e do lábio inferior, dor mandibular severa, maloclusões, entre outras. $(2,5) \mathrm{Em}$ adição, infecções bucais podem gerar bacteremias transitórias que podem evoluir para septicemias graves levando o indivíduo a óbito.(7,8)

Com base no exposto, torna-se mister a necessidade de uma participação efetiva do cirurgião dentista no contexto interdisciplinar da assistência ao portador da enfermidade. Em contraste, a literatura pesquisada evidenciou a carência de informações específicas a respeito do papel da Odontologia no contexto da atenção global ao portador de DF. No ano de 2007, o Ministério da Saúde publicou o "Manual de Saúde Bucal na DF", reconhecendo a necessidade de inserção da comunidade Odontológica neste contexto. ${ }^{(9)} \mathrm{Em}$ seguida, trabaIhos de Botelho et al (2009) e Mendes et al (2011), abordaram também especificamente as repercussões da enfermidade dentro do âmbito da Odontologia, permitindo-se inclusive a sugerir protocolos de atendimento e manuais de conduta. ${ }^{(2)}$ Já Ferraz et al (2007) salientaram a importância do diagnóstico precoce para sucesso no tratamento. ${ }^{(3)}$

Com relação às condições bucais e ao perfil sócio demográfico de pacientes portadores da enfermidade, Soares et al (2010) realizaram interessante trabalho investigando estas variáveis em crianças de 6 a 96 meses no Estado da Bahia, sendo um dos resultados do estudo a evidente necessidade de que se deve incrementar substancialmente a assistência odontológica a estes pacientes. ${ }^{(4)}$ Por outro lado, o único trabalho encontrado que investigou o perfil e grau de conhecimento de cirurgiões dentistas a respeito da abordagem ao portador de DF foi publicado por Coutinho et al em 2010. Neste estudo, a participação dos profissionais foi considerada insatisfatória e os resultados revelaram que há necessidade de se aprimorar estruturalmente os conhecimentos a respeito da doença e da inter-relação doença falciforme/Odontologia. ${ }^{(5)}$ Em adição, a literatura sobre o tema apresenta ma- joritariamente relatos clínicos, e poucos trabalhos analisaram epidemiologicamente os problemas bucais e a interação com a DF, ou seja, o impacto da doença na saúde oral ainda é inconclusivo, tornando difícil o desenvolvimento de políticas públicas de prevenção, que tem o objetivo de melhorar a qualidade de vida desses pacientes e reduzir os custos com tratamentos curativos. ${ }^{(10)}$

Neste contexto, o presente trabalho teve como objetivo obter informações atualizadas sobre o perfil e grau de conhecimento de diversas pessoas que se interessam ou estão envolvidas no tema "DF" e que participaram de um evento científico que abordou esta patologia.

\section{MATERIAIS E MÉTODOS}

O presente artigo apresenta um estudo onde se buscou, numa lógica descritiva, recolher informações sobre o perfil do entrevistado e o nível de conhecimento acerca da DF em participantes de um seminário sobre o referido tema. Com este propósito, foi aplicado um questionário semi-estruturado composto por 16 perguntas objetivas. O instrumento foi especialmente desenvolvido para o presente estudo e as perguntas foram estruturadas de forma a explorar os seguintes domínios: perfil do entrevistado, grau de conhecimento sobre DF, engajamento do entrevistado com DF, percepção sobre o ensino e treinamento em DF e o papel da Odontologia no contexto da DF. Não houve limitação de tempo para o preenchimento, sendo o questionário entregue aos entrevistados no início e recolhido ao final do evento. Não houve interferência dos entrevistadores e nem a possibilidade de esclarecimentos durante a coleta. O presente estudo contou com uma amostra de conveniência composta pelos participantes do seminário e que devolveram o questionário preenchido. Os objetivos do questionário, bem como os riscos e benefícios da pesquisa, foram explicados aos respondentes e um termo de consentimento livre e esclarecido foi em seguida firmado. A pesquisa foi submetida e aceita pelo Comitê de Ética da UFBA (CAAE 50563215.0.0000.5024). A participação foi 
voluntária e qualquer participante poderia remover seu consentimento durante as fases deste estudo.

O questionário foi aplicado na Faculdade de Odontologia da UFBA durante o seminário "O papel da Odontologia no contexto da atenção integral à DF". Para este evento, efetiva divulgação foi realizada. Cartazes foram confeccionados e fixados em "locais estratégicos" como: Secretaria Municipal de Saúde, APAE, ABO, CRO, Hospitais de Referência em DF e em murais de Universidades Públicas e Privadas. Foi realizado também panfletagem e exposição de banner na Faculdade de Odontologia da UFBA. Por fim, foram convidadas de forma virtual (e-mail) pessoas influentes na temática da DF e foi solicitado que as mesmas propagassem o convite em seus ambientes de trabalho. Sendo, portanto, esperado participação efetiva dos diversos interessados na temática.

\section{RESULTADOS}

Noventa pessoas participaram do seminário, sendo que 74 questionários foram respondidos e coletados. A pergunta número 1 versava sobre a atividade profissional de cada respondente, sendo esta pergunta o critério único para a divisão dos grupos do presente estudo, em que 4 (6\%) dos questionários foram respondidos por professores universitários (PU), 5 (7\%) por gestores em saúde (GS), 40 (54\%) por cirurgiões dentistas (CD), $21(28 \%)$ por acadêmicos do curso de Odontologia (AO), 2 (3\%) por acadêmicos de outros cursos de saúde (AS), $1(1 \%)$ por profissional da saúde excluindo-se Odontologia (PS) e 1 (1\%) questionário foi respondido por publico leigo (PL) (Figura 1). Para efeito de análise, acadêmicos de outros cursos de saúde, profissional de saúde (excluindo-se odontologia) e público leigo não tiveram os dados computados devido a baixa representatividade. Todos os professores participantes eram dentistas e lecionam em cursos de Odontologia; para efeito de análise os mesmos não foram computados no grupo "cirurgiões dentistas". Com relação ao grupo de gestores em saúde, nenhum entrevistado possuía graduação em Odontologia e nem exercia a profissão de professor universitário.

Figura 1 - Resultado referente a pergunta do questionário de número 1 "Qual a sua atividade profissional"

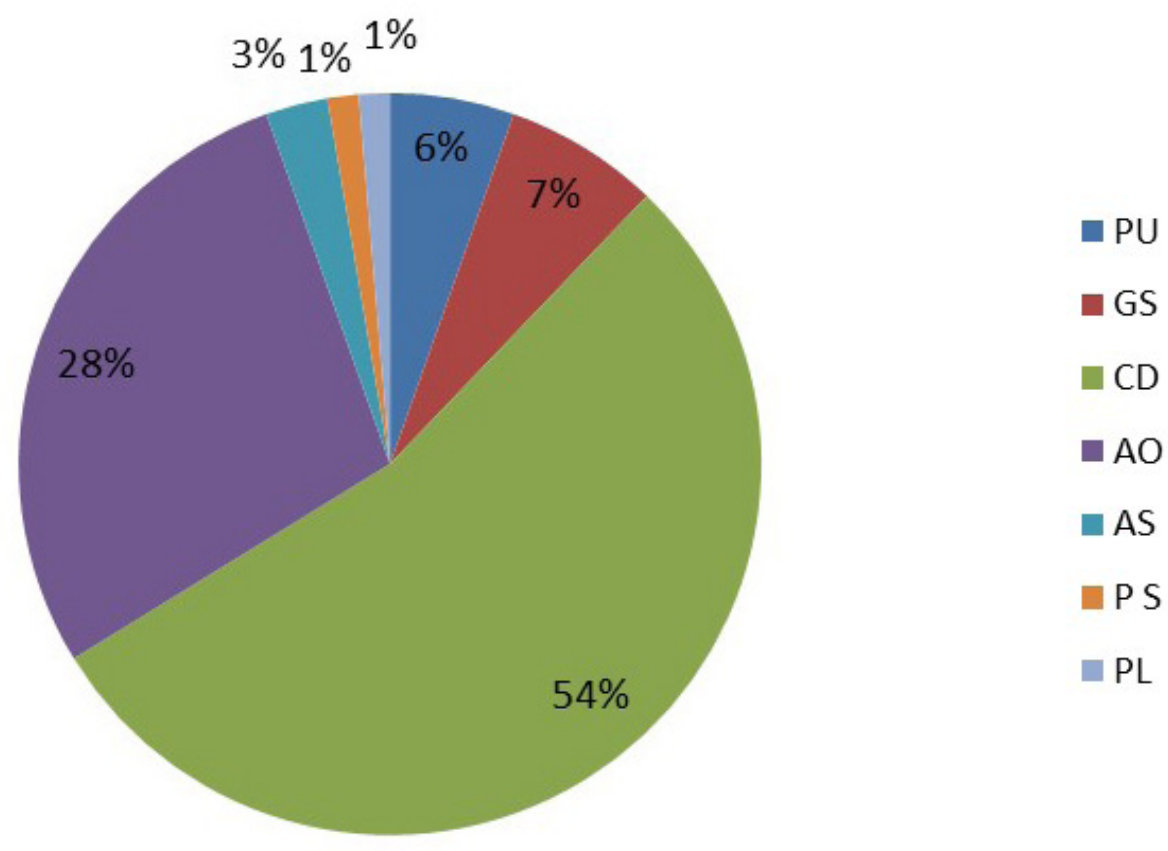


Os resultados detalhados referentes a cada pergunta foram distribuídos como se segue:

Pergunta 2: "De zero a dez, qual nota você atribui ao seu conhecimento sobre a DF". Nenhum respondente assinalou nota zero. Notas 1, 2, 3, 4, $5,6,7,8,9$ e 10 foram assinaladas por $1,3,5,6,14$, $9,17,11,2$ e 1 participantes, respectivamente. Cinco questionários foram entregues em branco. Den- tre os PU 1 respondeu nota 7, 2 responderam 8 e 1 nota 9. Dentre os GS, as notas 5, 6, 7, 8 e 10 foram assinaladas. Dentre os CD as notas de 1 a 10 foram respondidas por 1, 3, 3, 3, 6, 5, 9, 4, 1, o, respectivamente. Cinco questionários foram entregues em branco. Com relação aos $\mathrm{AO}$, a nota 3 foi assinalada por 2 pessoas e as notas $4,5,6$, 7, e 8 foram marcadas por 2, 6, 3, 5 e 3 respectivamente (Figura 2).

Figura 2 - Resultado referente a pergunta do questionário de número 2

\section{De zero a dez, qual nota você atribui ao seu conhecimento sobre a DF}

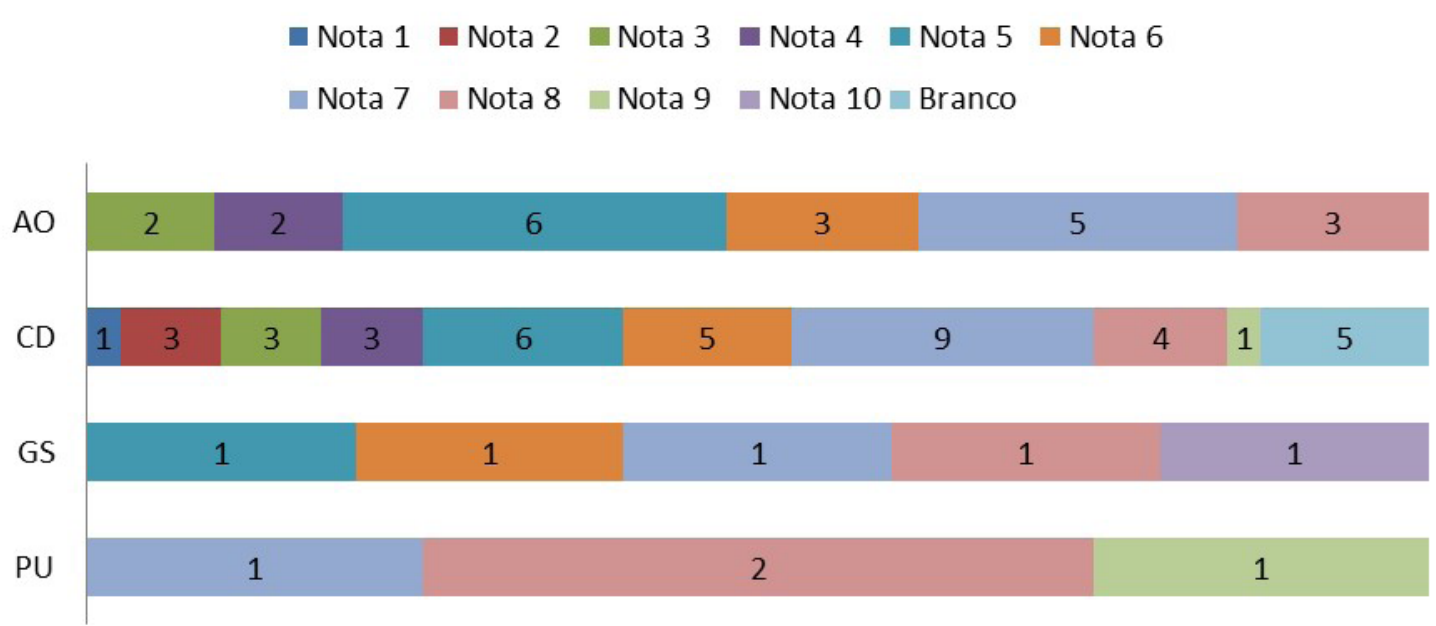

Pergunta 3: "Julga importante para sua profissão o conhecimento sobre a DF?" A esta indagação, dentre os PU, GS, CD e AO 100\% dos respondentes marcaram "sim" (Tabela 1).

Pergunta 4: "Já havia participado de algum evento abordando o tema DF?"No total $33(44,6 \%)$ respondentes disseram "sim" e 41 (55,4\%) "não". A distribuição das respostas "sim"foi encontrada como se segue: $25 \%$ entre os $\mathrm{PU}, 100 \%$ dos GS, $52 \%$ dos CD, 19\% dos AO (Tabela 1).

Pergunta 5: “Já havia participado de algum evento abordando especificamente a temática - "O papel da Odontologia dentro do contexto da DF?" No total $16(21,62 \%)$ respondentes disseram "sim" e 58 $(78,38 \%)$ "não". A distribuição das respostas "sim" foi encontrada como se segue: $25 \%$ entre os PU, 40\% dos CS, 29\% dos CD, $19 \%$ dos AO (Tabela 1).

Pergunta 6: "Julga o conhecimento ofertado em seu curso de graduação suficiente para o cuidado de pessoas com DF?" No total 7 (9,45\%) respondentes disseram "sim", 63 (85,15\%) responderam "não" e 4 (5,40\%) "não se aplica". A distribuição das respostas "sim" foi encontrada como se segue: $25 \%$ entre os PU, nenhum dos GS, 2,5\% dos CD, 23,8\% dos AO (Tabela 1).

Pergunta 7: "Conhece as implicações da DF para o tratamento odontológico ou dentro de sua área de atuação?". No total 42 (56,75\%) respondentes disseram "sim", $30(40,54 \%)$ responderam "não" e $2(2,71 \%)$ "não se aplica". A distribuição das res- 
postas "sim" foi encontrada como se segue: $100 \%$ entre os PU, $100 \%$ dos CS, $57,5 \%$ dos CD, 38,1\% dos AO (Tabela 1).

Pergunta 8: "Conhece os cuidados e particularidades que devem ser tomadas para o tratamento de pessoas acometidas por DF dentro de sua área de atuação?" No total 26 (35,13\%) respondentes disseram "sim", 26 (35,13\%) responderam "não" e 22 (29,74\%) "em parte". A distribuição das respostas foi encontrada como se segue: $100 \%$ de resposta "sim" entre os PU, 20\% dos GS responderam "sim" e 60\% "em parte". Dentre os CD 30\%, 37,5\% e 32,5\% responderam "sim" "não" e "em parte", respectivamente. Com relação aos $\mathrm{AO} 33,4 \%$ responderam "sim", 52,3\% "não" e 14,3\% responderam "em parte" (Tabela 1).

Pergunta 9: "Já teve a oportunidade de atender um paciente com DF?" No total 37 (50\%) respondentes disseram "sim", 32 (43,25\%) responderam "não" e 5 (6,75\%) "não se aplica". A distribuição das respostas foi encontrada como se segue: $50 \%$ de resposta "sim" e 50\% "não" entre os PU, 60\% dos CS responderam "sim" e $20 \%$ "não" ou "não se aplica". Dentre os CD 60\%, 35\% e 5\% responderam "sim" "não" e "não se aplica", respectivamente. Com relação aos AO 33,3\% responderam "sim", 61,9\% "não" e 4,76\% responderam "não se aplica" (Tabela 1).

Pergunta 10: "Acha que pessoas acometidas por DF buscarão pelo seu serviço de saúde?" No total $66(89,2 \%)$ respondentes disseram "sim", 1 $(1,35 \%)$ respondeu "não" e 7 (9,45\%) "não sei". A distribuição das respostas foi encontrada como se segue: $75 \%$ de resposta "sim" e $25 \%$ "não sei" entre os PU, $100 \%$ dos GS responderam "sim". Dentre os CD 92,5\% e 7,5\% responderam "sim" e "não sei", respectivamente. Com relação aos AO 85,71\% responderam "sim", 4,76\% "não" e 9,53\% responderam "não sei” (Tabela 1).

Pergunta 11: "Acha que as pessoas acometidas por DF devem procurar atendimento odontológico apenas em Centros Especializados?". No total $8(10,8 \%)$ respondentes disseram "sim" e 66 $(89,2 \%)$ responderam "não". A distribuição das respostas foi encontrada como se segue: $50 \%$ de resposta "sim" entre os PU, $100 \%$ dos CS responderam "não". Dentre os CD 7,5\% e 92,5\% responderam "sim" e" não" respectivamente. Com relação aos AO 14,3\% responderam "sim" e 85,7\% "não" (Tabela 1).

Pergunta 12: "Tem conhecimento de que a DF é rastreada em todos os recém-nascidos brasileiros pelo Programa Nacional de Triagem Neonatal do Ministério da Saúde, socialmente conhecido como teste do pezinho?" No total $58(78,4 \%)$ respondentes disseram "sim" e $16(21,6 \%)$ responderam "não". A distribuição das respostas foi encontrada como se segue: $100 \%$ de resposta "sim" entre os PU, 80\% dos GS responderam "sim". Dentre os CD 82,5\% e 17,5\% responderam "sim" e "não" respectivamente. Com relação aos AO 66,6\% responderam "sim" e 33,4\% "não" (Tabela 1).

Pergunta 13: "Tem conhecimento da Política de Atenção aos pacientes acometidos por DF?". No total 38 (51,35\%) respondentes disseram "sim" e 36 (48,65\%) responderam "não". A distribuição das respostas foi encontrada como se segue: $100 \%$ de resposta "sim" entre os PU e também entre os CS. Dentre os CD 42,5\% e $57,5 \%$ responderam "sim" e" não" respectivamente. Com relação aos $\mathrm{AO}$ 47,6\% responderam "sim" e 52,4\% "não" (Tabela 1).

Pergunta 14: "Acha que seminários, conferências, fóruns e congressos podem ajudar a difundir o conhecimento e melhorar a assistência a pessoas com DF?" Com relação a esta indagação, 100\% dos entrevistados responderam "sim" (Tabela 1).

Pergunta 15: "O evento - O papel da Odontologia no contexto da Atenção Integral a DF, ofertado no dia de hoje foi esclarecedor?". Com relação a esta indagação, 9,45\% dos respondentes deixaram em branco. Dentre os que assinalaram resposta, 100\% responderam "sim" (Tabela 1 ).

Pergunta 16: "Acha que se faz necessário um maior aprofundamento no conhecimento do papel da Odontologia dentro do contexto da atenção à DF?" Com relação a esta indagação, 100\% dos entrevistados responderam "sim" (Tabela 1). 
Tabela 1 - Resultados referentes as perguntas do questionário do número 3 a 16

\begin{tabular}{|c|c|c|c|c|c|c|c|c|c|c|c|c|c|c|c|}
\hline \multirow[b]{2}{*}{ Pergunts } & \multicolumn{3}{|c|}{ Professores Univ. } & \multicolumn{3}{|c|}{ Gestores de Saúde } & \multicolumn{3}{|c|}{ Cirurgiões Dentistas } & \multicolumn{3}{|c|}{ Acadêmicos Odontologia } & \multicolumn{3}{|c|}{ Total } \\
\hline & $\begin{array}{c}\text { Sim } \\
n \\
(\%)\end{array}$ & $\begin{array}{c}\text { Não } \\
n \\
(\%)\end{array}$ & $\begin{array}{c}\text { Outro } \\
n \\
(\%)\end{array}$ & $\begin{array}{c}\text { Sim } \\
n \\
(\%)\end{array}$ & $\begin{array}{c}\text { Não } \\
n \\
(\%)\end{array}$ & $\begin{array}{c}\text { Outro } \\
n \\
(\%) \\
\end{array}$ & $\begin{array}{c}\text { Sim } \\
n \\
(\%) \\
\end{array}$ & $\begin{array}{c}\text { Nã。 } \\
n \\
(\%)\end{array}$ & $\begin{array}{c}\text { Outro } \\
n \\
(\%)\end{array}$ & $\begin{array}{c}\text { Sim } \\
n \\
(\%) \\
\end{array}$ & $\begin{array}{c}\text { Não } \\
n \\
(\%)\end{array}$ & $\begin{array}{c}\text { Outro } \\
n \\
(\%)\end{array}$ & $\begin{array}{c}\mathrm{Sim} \\
n \\
(\%) \\
\end{array}$ & $\begin{array}{c}\text { Não } \\
n \\
(\%) \\
\end{array}$ & $\begin{array}{c}\text { Outro } \\
n \\
(\%)\end{array}$ \\
\hline n.3 & $\begin{array}{c}4 \\
(100,0)\end{array}$ & 0 & 0 & $\begin{array}{c}5 \\
(100,0)\end{array}$ & 0 & 0 & $\begin{array}{c}40 \\
(100,0)\end{array}$ & 0 & 0 & $\begin{array}{c}21 \\
(100,0)\end{array}$ & 0 & 0 & $\begin{array}{c}74 \\
(100.0)\end{array}$ & 0 & 0 \\
\hline n. 4 & $\begin{array}{c}1 \\
(25,0)\end{array}$ & $\begin{array}{c}3 \\
(75.0)\end{array}$ & - & $\begin{array}{c}5 \\
(100,0)\end{array}$ & 0 & - & $\begin{array}{c}21 \\
(52,5)\end{array}$ & $\begin{array}{c}19 \\
(47,5)\end{array}$ & - & $\begin{array}{c}4 \\
(19.0)\end{array}$ & $\begin{array}{c}17 \\
(81,0)\end{array}$ & - & $\begin{array}{c}33 \\
(44.6)\end{array}$ & $\begin{array}{c}41 \\
(55,4)\end{array}$ & - \\
\hline $\mathrm{n} .5$ & $\begin{array}{c}1 \\
(25,0)\end{array}$ & $\begin{array}{c}3 \\
(75.0)\end{array}$ & -- & $\begin{array}{c}2 \\
(40,0)\end{array}$ & $\begin{array}{c}3 \\
(60,0)\end{array}$ & - & $\begin{array}{c}8 \\
(22,5)\end{array}$ & $\begin{array}{c}31 \\
(77,5)\end{array}$ & - & $\begin{array}{c}4 \\
(19.0)\end{array}$ & $\begin{array}{c}17 \\
(81,0)\end{array}$ & - & $\begin{array}{c}16 \\
(21.62)\end{array}$ & $\begin{array}{c}58 \\
(78.38)\end{array}$ & - \\
\hline$n \cdot 6$ & $\begin{array}{c}1 \\
(25.0)\end{array}$ & $\begin{array}{c}3 \\
(75,0)\end{array}$ & 0 & 0 & $\begin{array}{c}3 \\
(60,0)\end{array}$ & $\begin{array}{c}2 \\
(40,0)\end{array}$ & $\begin{array}{c}1 \\
(2,5)\end{array}$ & $\begin{array}{c}39 \\
(97,5)\end{array}$ & 0 & $\begin{array}{c}5 \\
(23,80)\end{array}$ & $\begin{array}{c}16 \\
(76,20)\end{array}$ & 0 & $\begin{array}{c}7 \\
(8.45)\end{array}$ & $\begin{array}{c}63 \\
(85.15)\end{array}$ & $\begin{array}{c}4 \\
(5,40)\end{array}$ \\
\hline$n .7$ & $\begin{array}{c}4 \\
(100,0)\end{array}$ & 0 & 0 & $\begin{array}{c}5 \\
(100,0)\end{array}$ & 0 & 0 & $\begin{array}{c}23 \\
(57,5)\end{array}$ & $\begin{array}{c}16 \\
(40,0)\end{array}$ & $\begin{array}{c}1 \\
(2,50)\end{array}$ & $\begin{array}{c}8 \\
(38.10)\end{array}$ & $\begin{array}{c}12 \\
(57,14)\end{array}$ & $\begin{array}{c}1 \\
(4.76)\end{array}$ & $\begin{array}{c}42 \\
(56,75)\end{array}$ & $\begin{array}{c}30 \\
(40.54)\end{array}$ & $\begin{array}{c}2 \\
(2,71)\end{array}$ \\
\hline n.8 & $\begin{array}{c}4 \\
(100,0)\end{array}$ & 0 & 0 & $\begin{array}{c}2 \\
(40,0)\end{array}$ & 0 & $\begin{array}{c}3 \\
(60,0)\end{array}$ & $\begin{array}{c}12 \\
(30,0)\end{array}$ & $\begin{array}{c}15 \\
(37,50)\end{array}$ & $\begin{array}{c}13 \\
(32,50)\end{array}$ & $\begin{array}{c}7 \\
(33,4)\end{array}$ & $\begin{array}{c}11 \\
(52,30)\end{array}$ & $\begin{array}{c}3 \\
(14,3)\end{array}$ & $\begin{array}{c}26 \\
35.13\end{array}$ & $\begin{array}{c}26 \\
35,13\end{array}$ & $\begin{array}{c}22 \\
29,74\end{array}$ \\
\hline n. 8 & $\begin{array}{c}2 \\
(50,0)\end{array}$ & $\begin{array}{c}2 \\
(50,0)\end{array}$ & 0 & $\begin{array}{c}3 \\
(60,0)\end{array}$ & $\begin{array}{c}1 \\
(20,0)\end{array}$ & $\begin{array}{c}1 \\
(20.0)\end{array}$ & $\begin{array}{c}24 \\
(60,0)\end{array}$ & $\begin{array}{c}14 \\
(35,0)\end{array}$ & $\begin{array}{c}2 \\
(5.0)\end{array}$ & $\begin{array}{c}7 \\
(33,4)\end{array}$ & $\begin{array}{c}13 \\
(61,84)\end{array}$ & $\begin{array}{c}1 \\
(4.76)\end{array}$ & $\begin{array}{c}37 \\
(50.0)\end{array}$ & $\begin{array}{c}32 \\
(43.25)\end{array}$ & $\begin{array}{c}5 \\
(6.75)\end{array}$ \\
\hline n. 10 & $\begin{array}{c}3 \\
(75,0)\end{array}$ & 0 & $\begin{array}{c}1 \\
(25,0)\end{array}$ & $\begin{array}{c}5 \\
(100,0)\end{array}$ & 0 & 0 & $\begin{array}{c}37 \\
(82,50)\end{array}$ & 0 & $\begin{array}{c}3 \\
(7,50)\end{array}$ & $\begin{array}{c}18 \\
(85.71)\end{array}$ & $\begin{array}{c}1 \\
(4,76)\end{array}$ & $\begin{array}{c}2 \\
(8,53)\end{array}$ & $\begin{array}{c}66 \\
(89.2)\end{array}$ & $\begin{array}{c}1 \\
(1.35)\end{array}$ & $\begin{array}{c}7 \\
(9.45)\end{array}$ \\
\hline n. 11 & $\begin{array}{c}2 \\
(50,0)\end{array}$ & $\begin{array}{c}2 \\
(50,0)\end{array}$ & -- & 0 & $\begin{array}{c}5 \\
(100,0)\end{array}$ & - & $\begin{array}{c}3 \\
(7.50)\end{array}$ & $\begin{array}{c}37 \\
(92,5)\end{array}$ & - & $\begin{array}{c}3 \\
(14.3)\end{array}$ & $\begin{array}{c}18 \\
(85.7)\end{array}$ & - & $\begin{array}{c}8 \\
(10.8)\end{array}$ & $\begin{array}{c}66 \\
(89.2)\end{array}$ & - \\
\hline n. 12 & $\begin{array}{c}4 \\
(100,0)\end{array}$ & 0 & - & $\begin{array}{c}4 \\
(80,0)\end{array}$ & $\begin{array}{c}1 \\
(20,0)\end{array}$ & - & $\begin{array}{c}33 \\
(82,5)\end{array}$ & $\begin{array}{c}7 \\
(17,5)\end{array}$ & - & $\begin{array}{c}14 \\
(66,6)\end{array}$ & $\begin{array}{c}7 \\
(33,4)\end{array}$ & - & $\begin{array}{c}58 \\
(78.4)\end{array}$ & $\begin{array}{c}16 \\
(21,6)\end{array}$ & - \\
\hline ก. 13 & $\begin{array}{c}4 \\
(100.0)\end{array}$ & 0 & -- & $\begin{array}{c}5 \\
(100,0)\end{array}$ & 0 & - & $\begin{array}{c}17 \\
(42,50)\end{array}$ & $\begin{array}{c}23 \\
(57,5)\end{array}$ & - & $\begin{array}{c}10 \\
(47.60)\end{array}$ & $\begin{array}{c}11 \\
(52,40)\end{array}$ & - & $\begin{array}{c}38 \\
(51,35)\end{array}$ & $\begin{array}{c}36 \\
(48,65)\end{array}$ & - \\
\hline ก. 14 & $\begin{array}{c}4 \\
(100,0)\end{array}$ & 0 & - & $\begin{array}{c}5 \\
(100,0)\end{array}$ & 0 & - & $\begin{array}{c}40 \\
(100,0)\end{array}$ & 0 & - & $\begin{array}{c}21 \\
(100,0)\end{array}$ & 0 & - & $\begin{array}{c}74 \\
(100.0)\end{array}$ & 0 & - \\
\hline n. 15 & $\begin{array}{c}4 \\
(100,0)\end{array}$ & 0 & -- & $\begin{array}{c}5 \\
(100,0)\end{array}$ & 0 & - & $\begin{array}{c}35 \\
(87.50)\end{array}$ & - & $\begin{array}{c}5 \\
(12,50)\end{array}$ & $\begin{array}{c}18 \\
(90,47)\end{array}$ & - & $\begin{array}{c}2 \\
(9,53)\end{array}$ & $\begin{array}{c}67 \\
(90.55)\end{array}$ & - & $\begin{array}{c}7 \\
(9.45)\end{array}$ \\
\hline n. 16 & $\begin{array}{c}4 \\
(100,0)\end{array}$ & 0 & - & $\begin{array}{c}5 \\
(100,0)\end{array}$ & 0 & - & $\begin{array}{c}39 \\
(97.5)\end{array}$ & - & $\begin{array}{c}1 \\
(2,50)\end{array}$ & 21 & 0 & - & $\begin{array}{c}73 \\
(98,65)\end{array}$ & - & $\begin{array}{c}1 \\
(1,35)\end{array}$ \\
\hline
\end{tabular}

\section{DISCUSSÃO}

A DF é a enfermidade de caráter hereditário mais prevalente no Brasil, sendo a Bahia o estado com maior número de indivíduos acometidos. ${ }^{(1,2)}$ A DF é uma condição de alto grau de morbidade e mortalidade, sendo, portanto, considerada um problema de saúde pública. O cuidado do doente requer a atuação de uma equipe multidisciplinar na qual a inserção efetiva do cirurgião dentista torna-se cada vez mais necessária. Neste ínterim, o presente estudo visou trazer elementos que elucidem o status atual do dentista dentro da atenção global ao paciente com DF.

A literatura consultada evidenciou que há pouco conhecimento formalizado sobre este assunto.
A maioria dos estudos visa discorrer sobre os aspectos fisiopatológicos de interesse para a Odontologia e, por fim, propor condutas e protocolos terapêuticos. ${ }^{(11,12)}$ Esta realidade parece-nos bastante legítima e provavelmente traduza um atraso da Odontologia dentro do contexto multidisciplinar de atenção. O primeiro manual de conduta odontológica para DF foi lançado em 2007, sendo que desde 1992 a doença é rastreada pelo programa de triagem neo natal em todo território nacional. $(9,1)$

Foi bastante interessante notar o interesse dos cirurgiões dentistas em DF. Neste estudo, $54 \%$ da plateia era composta por profissionais formados. Vários motivos podem ser atribuídos a esta constatação. Especula-se que a experiência de atendimento de pacientes com DF no dia-a-dia na cidade de 
Salvador associado ao pouco conhecimento disponível sobre esse tema sejam os fatores motivacionais mais relevantes. Os dados aferidos pela pergunta 3 reforçam este achado. Na pergunta 5 , que versava sobre a oportunidade de participar de eventos sobre DF específicos para odontologia, apenas $29 \%$ dos CD haviam participado, o que ratifica a necessidade de incrementar este tipo de atividade.

Apesar do interesse em aprender, os profissionais consultados relataram possuir pouco conhecimento sobre DF. Na literatura consultada, o único estudo encontrado que avaliou o nível de conhecimento de profissionais de odontologia sobre DF evidenciou em uma amostra de Odontopediatras que o tema é ainda motivo de dúvidas. No estudo, $62,5 \%$ dos respondentes afirmaram não ter recebido nenhuma informação sobre DF durante o curso de pós-graduação. ${ }^{(5)}$

Dado também importante, e de certa forma decepcionante, foi a participação dos acadêmicos de Odontologia. Apesar da massiva divulgação e gratuidade do evento, apenas $28,37 \%$ da plateia era composta por estudantes. Esta constatação é preocupante quando se avaliou que apenas 2,5\% dos profissionais formados consideram suficiente o conteúdo sobre DF ofertado na graduação. Parece haver uma maior conscientização a respeito da relevância deste tema após a conclusão do curso. Por outro lado, $100 \%$ da plateia considerou palestras e seminários instrumentos importantes na aquisição de conhecimento e melhoria do atendimento ao doente. Infere-se, portanto, que os professores devem fortalecer esse tipo de atividade e incentivar a participação discente.

Quase $90 \%$ da plateia afirmou que os pacientes com DF não deveriam procurar atendimento apenas em centros especializados. $\mathrm{Na}$ visão dos autores, esta foi uma constatação positiva já que se acredita na importância da universalização e democratização do atendimento. Logicamente, isso envolve busca de conhecimento e capacitação.

A participação de professores universitários e de gestores em saúde foi uma grata constatação no presente trabalho. A formação de conhecimento e aplicação nas políticas de saúde são obviamente fundamentais na evolução da qualidade do atendimento. De acordo com os resultados, $100 \%$ da plateia acha necessário aprofundar o conhecimento sobre DF. A interação entre poder público, academia e sociedade se fez presente no evento, o que se considera um ótimo instrumento de comunicação, visto que quase metade da plateia não conhece as políticas aplicadas em DF.

O presente estudo apresenta a percepção de conhecimento sobre DF em uma amostra bem específica, devendo, portanto, ser interpretado sob ótica bastante crítica. Em adição, os dados foram coletados no Estado que provavelmente sofre a maior repercussão física e social da doença. Apesar destas limitações, informações interessantes puderam ser extraídas e espera-se que este estudo possa incentivar outras ações que conduzam a uma agenda positiva dentro do contexto do atendimento odontológico ao portador de doença falciforme no Brasil.

\section{AGRADECIMENTOS}

Os autores do estudo gostariam de manifestar os sinceros agradecimentos a Embaixada do Japão no Brasil, a Japan International Cooperation Agency, ao Ministério da Saúde do Brasil, à Faculdade de Odontologia da Universidade Federal da Bahia e à Associação Brasiliense de Ex Bolsistas Brasil Japão por terem proporcionado a realização do seminário, seja com patrocínio financeiro ou apoio logístico.

\section{REFERÊNCIAS}

1. Cançado RD, Jesus JA. Sickle cell disease in Brazil. Rev. bras. hematol. hemoter. 2007; 29(3):204-6.

2. Botelho DS, Vergne AA, Bittencourt S, Ribeiro EDP. Sistemic profile and clinical dental procedures in patientes with sickle cell disease. Int. j. dent. 2009; 8(1):28-35. 
3. Ferraz MHC, Murao M. Laboratorial diagnosis of sickle cell disease in the neonate and after the sixth month of life. Rev. bras. hematol. hemoter. 2007; 29(3):218-22.

4. Soares FF, Rossi TRA, Brito MGS, Vianna MIP, Cangussu MCT. Conditions of oral health and socio-demographic factors in children from 6 to 96 months with sickle cell disease of Bahia. Rev. odontol. UNESP. 2O10;39(2):115-21.

5. Coutinho TCL. Evaluation of the clinical care of children with sickle cell anemia by pediatric dentists from Rio de Janeiro, RJ, Brazil. Rev. flum. odontol. 2010; 33:20-6.

6. Ministério da Saúde (BR), Secretaria de Atenção à Saúde, Departamento de atenção especializada. Manual de condutas básicas na doença falciforme. Brasília: Ministério da Saúde; 2006.

7. Agência Nacional de Vigilância Sanitária (BR). Manual de diagnóstico e tratamento de doença falciforme. Brasília: Agência Nacional de Vigilância Sanitária; 2002.

8. Alves PVM, Alves DKM, Souza MMG, Torres SR. Orthodontic treatment of patients with sickle cell anemia. Angle orthod. 2006; 76(2):269-73.

9. Ministério da Saúde (BR), Secretaria de Atenção à Saúde, Departamento de atenção especializada. Manual de saúde bucal na doença falciforme. Brasília: Ministério da saúde, 2007.

10. Passos CP. Análise da prevalência de alterações bucais em pacientes com doença falciforme [dissertação]. Salvador: Universidade Federal da Bahia; 2010.

11. Hosni JS, Fonseca MS, Cruz RA, Silva LCP. Dental treatment protocol for sickle cell anemia patient. Arq. bras. odontol. 2008; 4(2):104-12.

12. Rodrigues MJ, Menezes VA, Luna ACA. Oral health in patients with cell anemia. Rev. gauch. odontol. 2013; 61(0):505-10. 